\title{
Investigation of Mechanical and Wear Properties of LM24/Silicate/Fly Ash Hybrid Composite Using Vortex Technique
}

\author{
B. R. Senthil Kumar, ${ }^{1}$ M. Thiagarajan, ${ }^{2}$ and K. Chandrasekaran ${ }^{3}$ \\ ${ }^{1}$ Department of Mechanical Engineering, Nehru Institute of Engineering and Technology, Coimbatore, Tamil Nadu 641008, India \\ ${ }^{2}$ Department of Mechanical Engineering, SNS College of Technology, Coimbatore, Tamil Nadu 641107, India \\ ${ }^{3}$ Department of Mechanical Engineering, Nadar Saraswathi College of Engineering and Technology, Theni 625531, India \\ Correspondence should be addressed to BR. Senthil kumar; senthilramanseetha@yahoo.com
}

Received 29 December 2015; Revised 27 April 2016; Accepted 17 May 2016

Academic Editor: Pavel Lejcek

Copyright ( 2016 BR. Senthil kumar et al. This is an open access article distributed under the Creative Commons Attribution License, which permits unrestricted use, distribution, and reproduction in any medium, provided the original work is properly cited.

\begin{abstract}
This work has investigated to find the influence of silicate on the wear behavior of LM 24/4 wt.\% fly ash hybrid composite. The investigation reveals the effectiveness of incorporation of silicate in the composite for gaining wear reduction. Silicate particles with fly ash materials were incorporated into aluminum alloy matrix to accomplish reduction in wear resistance and improve the mechanical properties. The LM24/silicate/fly ash hybrid composite was prepared with 4 wt.\% fly ash particles with 4, 8, 12, 16, 20, and $24 \mathrm{wt} . \%$ of silicate using vortex technique. Tribological properties were evaluated under different load (15, 30, 45, 60, and 75 N); sliding velocity $(0.75,1.5,2.25$, and $3 \mathrm{~m} / \mathrm{sec})$ condition using pin on disc apparatus and mechanical properties like density, hardness, impact strength, and tensile strength of composites were investigated. In addition, the machining of the aluminum hybrid composite was studied using Taguchi $\mathrm{L}_{9}$ orthogonal array with analysis of variance. The properties of the hybrid composites containing $24 \mathrm{wt} . \%$ silicates exhibit the superior wear resistance and mechanical properties.
\end{abstract}

\section{Introduction}

Aluminum metal matrix composites are used in functional applications such as thermal management fields, defense, automotive field, and aerospace [1]. Aluminum metal matrix composites are used to manufacture light weight products owing to their high specific mechanical properties and low density. Ceramic materials are generally hard and brittle component which is used to disperse into the matrix to obtain properties that are superior to conventional alloys [2]. Aluminum alloys are preferred due to their high strength to weight ratio, corrosion resistance properties, and abundance in nature. But their advantages are low owing to low wear resistance property. Hybrid composites are widely used as substitution of metal matrix composites for improving their physical properties [3]. Metal matrix composites consist of two materials with one being metal; the other can be of different material that acts as reinforcement. Metal matrix composites comprising three constituents are called hybrid composites and reinforcements are also used to improve the properties of metal matrix composites [4,5]. Aluminum with silicate and fly ash hybrid composites are combined with high specific strength and good corrosion resistance which are used in various engineering applications. The reinforcement ceramic materials such as $\mathrm{SiC}, \mathrm{Al}_{2} \mathrm{O}_{3}$, and $\mathrm{TiB}$ are costlier. Silicate particulates obtained from naturally available rock represent an attractive dispersoid to provide low cost metal matrix composites [6]. Silicate is available in large quantities having hardness values of $981-1161 \mathrm{Hv}$, which is composed of alumina silicates of calcium, which is chemically inert even at higher temperatures. It softens at temperatures of $1413 \mathrm{~K}-$ $1553 \mathrm{~K}$ [7]. Fly ash is one of the most inexpensive and low density reinforcements available in large quantities as solid waste by product during combustion of coal in thermal power plants. Hence, composites with fly ash as reinforcement are likely to overcome the cost barrier for wide spread 
applications [8]. It is expected that the incorporation of fly ash and silicate particles reinforced aluminum composites which are gaining importance because of their low cost with advantages like isotropic properties [9].

The researchers developed aluminum metal matrix composites in many commercial and industrial applications and the related valuable studies presented by the past researchers are reviewed. Sulardjaka and Wildan [10] developed a wear rate prediction model for aluminum based composites reinforced with 10 and $30 \mathrm{wt} . \%$ in situ aluminum diboride flakes using Taguchi's method. The experimental results described that the normal load and reinforcement ratio were the major parameters influencing the specific wear rate for all samples. Gopalakannan et al. [11] developed aluminum metal matrix composites reinforced with titanium carbide for improving the high specific strength, high temperature, and wear resistance. $\mathrm{Al} / \mathrm{TiC}$ castings with different volume fraction of $\mathrm{TiC}$ were produced in an argon atmosphere by an enhanced stir casting method and result of the study is specific strength of the composite which is increased with higher percentage of $\mathrm{TiC}$ addition. Karthikeyan [12] studied the properties of aluminum-SiC-fly ash hybrid metal matrix composites. The properties of metal matrix composites like density, tensile strength, yield strength, elongation, and hardness tests were conducted. It was observed that the density of the composites was decreased, hardness was increased, and there was increase in tensile strength but elongation of the hybrid metal matrix composite is decreased compared to unreinforced aluminum alloy. Anantha Prasad and Nityanand [13] developed a hybrid composite of aluminum alloy with garnet and carbon particulate reinforcements using chill casting technique. Chills of various materials such as copper, steel, iron, and silicon carbide were used to accelerate the solidification. Combination of dispersoid varies from 3 to $12 \mathrm{wt} . \%$ in steps of 3 percentages of garnet and 3 percentages of carbon particulates. The results confirmed that there was a positive relationship between mechanical behavior and the dispersoid content. The copper chill cast composite with $9 \mathrm{wt} . \%$ garnet and $3 \mathrm{wt} . \%$ carbon was found to increase mechanical properties. Radhika et al. [14] investigated the wear behavior of $\mathrm{Al}-\mathrm{Si}_{10} \mathrm{Mg}$ alloy reinforced with $3 \mathrm{wt} . \%$ graphite and $9 \mathrm{wt} . \%$ alumina for the second phase. It was concluded that the incorporation of graphite as primary reinforcement increased the wear resistance of composites and the inclusion of alumina as a secondary reinforcement also had a significant effect on the wear behavior. Kumar et al. [15] developed $\mathrm{Al}_{4} \mathrm{SiC}_{4}$ using in situ incorporation of $\mathrm{TiC}$ particles into commercial aluminum melt through stir casting method. The overall wear rate increased with load in alloy as well as in the composite. The in situ $\mathrm{Al}_{4} \mathrm{SiC}_{4}$ particles offered resistance to adhesive wear. Mitrovic et al. [7] investigated aluminum metal matrix composites with multiple reinforcements which increased applications because of improved mechanical and tribological properties. Multiple reinforcements are better substitutes for single reinforced composites. The result shows that hybrid composites possess higher hardness, higher tensile strength, better wear resistance, and lower coefficient of friction when compared to pure alloys.
Ravi Kumar et al. [9] reported the evaluation of aluminum alloy composites reinforced with fly ash particles of three different size ranges 53-75, 75-103, and 103-150 $\mu \mathrm{m}$ in $3,6,9$, and $12 \mathrm{wt} . \%$. The pin on disc wear tests was conducted with 20,30, and $40 \mathrm{~N}$ loads and sliding speeds of 2, 3, and $4 \mathrm{~m} / \mathrm{s}$ for a constant time period of $10 \mathrm{~min}$. Composites reinforced with coarse fly ash particles exhibit superior wear resistance to those reinforced with fine fly ash particles. Sivakumar et al. [16] reported that aluminum metal matrix composites are successfully produced using stir casting route up to $20 \mathrm{wt} . \%$ of fly ash. The hardness of aluminum fly ash composites has increased with increase with addition of fly ash. In the aluminum melt, both the frictional forces and the wear rates have decreased significantly with the incorporation of fly ash. Researches have been carried out on the mechanical and wear properties of aluminum metal matrix composites with different reinforcement materials. In the case of hybrid LM24 alloy composites, limited literature is available encompassing various aspects such as mechanical properties and wear behavior of aluminum alloy metal matrix composites. Palanikumar et al. [17] studied the optimum machining conditions for turning of particulate metal matrix composite. In this study, carbide tools were used for turning particulate metal matrix composite instead of using poly crystalline diamond tool, since it increases the cost of production. The effect of machining parameters on the surface roughness was evaluated and optimum machining conditions for maximizing the metal removal rate and minimizing the surface roughness were determined. Paulo Davim [18] investigated the drilling metal matrix composites of type A356/20\% SiC-T6 based on the Taguchi technique with the objective of establishing the correlations between cutting velocity, feed, and cutting time with the evaluation of tool wear, the specific cutting pressure, and the hole surface roughness using polycrystalline diamond tool. Manna and Bhattacharayya [19] presented a study on machinability of $\mathrm{Al} / \mathrm{SiC}$ and the influence of turning parameters on the cutting force and surface finish criteria were investigated during experimentation using fixed rhombic tools, which is otherwise usually machined by costly polycrystalline diamond tool or cubic boron nitride tools. Tosun and Muratoglu [20] investigated the effect of the various cutting parameters on the surface quality and microstructure on drilling of $2124 \mathrm{Al} / 17 \% \mathrm{SiC}$ particulate metal matrix composite by using various drills. The influence of the type of drills, point angles of drills, and ageing on the drilling performance of aluminum alloy reinforced with $\mathrm{SiC}$ particulates was investigated experimentally. The researchers concluded that if the results form an estimate of economic factors, the TiN coated HSS drills which are cheaper than solid carbide tools have been suggested for drilling $\mathrm{Al} / \mathrm{SiC}$. Summarizing the literature, it can be stated that a good volume of research has been carried out on the mechanical and wear properties and machining characteristics of aluminum metal matrix composites with different reinforcement materials. In the case of hybrid LM24 alloy composites, limited literature is available encompassing various aspects such as mechanical properties and wear behavior of aluminum alloy metal matrix composites and conducted the machining study of 
the composites and conducted the design of experiments of the composites. But tribological studies and optimization machining parameters for drilling on LM24/silicate/fly ash hybrid composite under different conditions have not been reported so far. Hence in this research work an attempt is made to study the wear behavior, mechanical properties, and machining characteristics on LM24/silicate/fly ash hybrid composite.

\section{Materials and Methods}

2.1. Material Fabrication. The dissolving was done in an electrical resistance heater and vortex technique was embraced to set up the composite examples. The melt was maintained at a temperature between $1025 \mathrm{~K}$ and $1075 \mathrm{~K}$ for an hour. Two thermocouples and one proportional integral derivative controller were used and temperature of the furnace was precisely measured and controlled in order to achieve sound quality composite. The composite was prepared with LM 24 aluminum alloy with silicate and fly ash and the chemical composition of the LM 24 is given in Table 1 . Silicate particles of 100 mesh sizes varying from 4 to $24 \mathrm{wt} . \%$ in steps of $4 \mathrm{wt} . \%$ were used to prepare the composites. Fly ash consists of refractory oxides like silica, alumina, and iron oxides at the proportion of $4 \mathrm{wt}$ \% reinforcing phase. The aluminite coated mechanical stirrer is necessary in order to prevent the migration of ferrous ions from the stirrer into the matrix alloy melt. The silicate was preheated to a temperature of $713 \mathrm{~K}$ and then introduced into the slurry. The stirring is continued until particle and matrix wetting occurs. Finally, the melt was degassed and deslagged and the refined metal was poured into cylindrical mold. After the mold was cooled down to the room temperature, the specimens were taken out and cut to required dimension.

2.2. Tribology Procedure of Hybrid Composites. Wear test was carried out using pin on disc apparatus and pins were tested against the steel disc possessing the hardness of $62 \mathrm{HRC}$. Prior to the tests, the pins were polished with a SiC-1200 grit polishing paper and cleaned with acetone. The tribological tests were conducted with the applied load range of $15-75 \mathrm{~N}$ in step of $15 \mathrm{~N}$ at sliding velocities of 0.75 to $3 \mathrm{~m} / \mathrm{s}$ in step of $0.75 \mathrm{~m} / \mathrm{s}$ and with a constant sliding distance of $3000 \mathrm{~m}$. The volume loss of the pin was calculated before and after each wear test utilizing an electronic digital weight balance with an accuracy of $0.1 \mathrm{mg}$. All these tests were conducted at room temperature $300 \mathrm{~K}$ and relative humidity of $48 \%$. Metallurgical microscope was used to capture the microstructure of the composite and scanning electron microscope was used to study the morphology of the composite.

2.3. Machining Procedure of Hybrid Composites. The drilling tests were conducted on radial drilling machine and experiments carried out on work materials were cut into plates of about $200 \times 100 \times 20 \mathrm{~mm}$. Equal spacing is maintained between successive drilled holes in the plate. TiAlN coated drill bit was used throughout the experiment work. The angle included between the cutting lips projected upon
TABLE 1: Chemical composition of aluminum LM24.

\begin{tabular}{cccccccccc}
\hline $\mathrm{Mg}$ & $\mathrm{Si}$ & $\mathrm{Fe}$ & $\mathrm{Cu}$ & $\mathrm{Ti}$ & $\mathrm{Zn}$ & $\mathrm{Mn}$ & $\mathrm{Ni}$ & $\mathrm{Pb}$ & $\mathrm{Al}$ \\
\hline 0.3 & 9.5 & 1.3 & 3 & 0.2 & 3 & 0.5 & 0.5 & 3 & $\mathrm{Bal}$ \\
\hline
\end{tabular}

TABLE 2: Factors and levels selected for drilling operation.

\begin{tabular}{lccc}
\hline Factors & \multicolumn{3}{c}{ Levels } \\
& 1 & 2 & 3 \\
\hline Cutting speed $(A)(\mathrm{m} / \mathrm{min})$ & 30 & 60 & 90 \\
Feed $(B)(\mathrm{mm} / \mathrm{rev})$ & 0.5 & 1 & 1.5 \\
Point angle $(C)$ (degree) & 100 & 120 & 140 \\
\hline
\end{tabular}

a plane parallel to the drill axis and parallel to the two cutting lips is called point angle. In the analysis on the effect of the point angles on surface texture, it was evident that the significant change in the surface roughness was associated with an increase in the point angles resulting in a change in the surface texture. The responses such as average surface roughness $(\mathrm{Ra})$ and cutting force $(\mathrm{Fc})$ which are mostly used in industries are taken for this study. The cutting force and toque were measured using strain gauge dynamometer and surface roughness was measured using Surfertest 211. Hence, in this work, cutting speed, feed, and point angle of drill were identified as factors for the objective of minimization of surface roughness and cutting force. In this work, three factors each set at three levels were selected for the experimentation. Table 2 demonstrates the variables picked and their levels utilized as a part of this work.

\section{Result and Discussions}

3.1. Mechanical Properties of Hybrid Composites. The effect of LM24/4 wt.\% fly ash and varying wt.\% of silicate on the hardness, tensile strength, and density of the hybrid composite obtained from test are shown in Figures 1(a)-1(c). The hardness measurements were carried out on a Vickers hardness testing machine. From Figure 1(a), it is observed that the hardness of the LM24/silicate/fly ash hybrid composite increases with the addition of silicate and it is higher than that of base alloy. Hardness of all the hybrid composites was significantly greater than that of the base alloy characterized to the hard nature of silicate particles. The higher hardness values for the hybrid composites containing Al (24 wt.\% silicate and 4 wt.\% fly ash) are due to the presence of hard silicate particles. Tensile test specimens were made as per the ASTM standard and tested in a Universal Testing Machine. As per the requirements of tensile testing standards of ASTM, E8, the samples were machined into cylindrical shape, before measuring the tensile strength. The tests were carried out at room temperature with a minimum cross head speed of $0.5 \mathrm{~mm} / \mathrm{min}$. The variation of ultimate tensile strength with varying wt.\% of silicate was illustrated in Figure 1(b).

The tensile strength was increased with increasing silicate content. The fly ash addition normally decreases the strength but, with the addition of silicate particles, improves the mechanical properties from the LM24/silicate/fly ash hybrid composite. Density measurements were carried out on the 


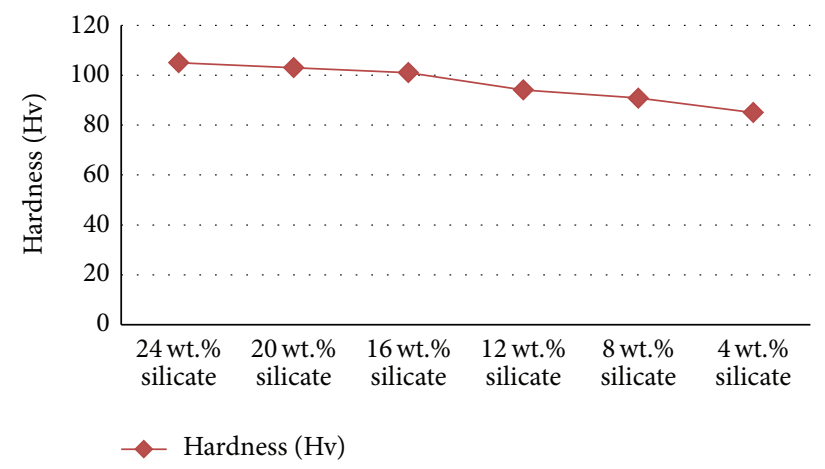

(a)

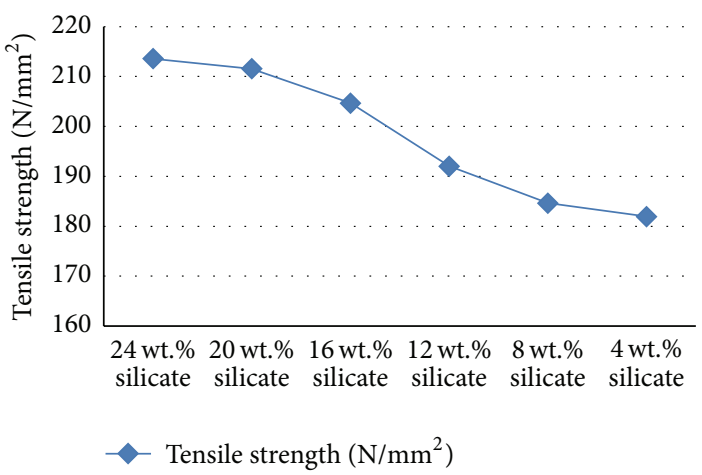

(b)

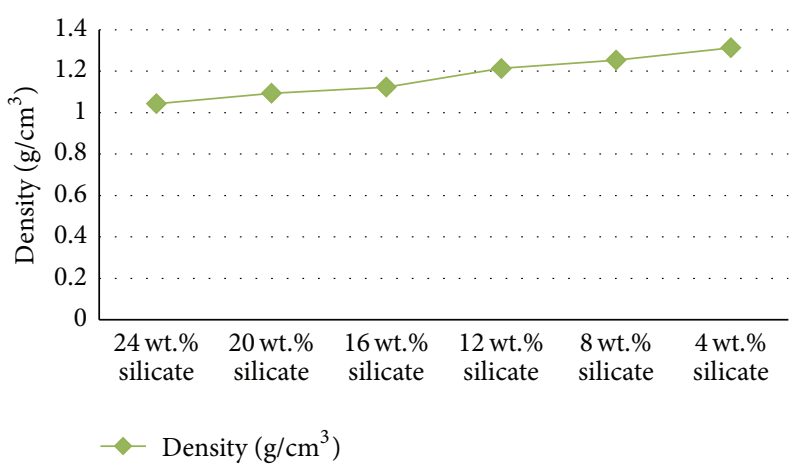

(c)

FIGURE 1: (a) Hardness of LM24/silicate/fly ash hybrid composite. (b) Tensile strength of LM24/silicate/fly ash hybrid composite. (c) Density of LM24/silicate/fly ash hybrid composite.

base LM24/silicate/fly ash hybrid composite samples using the Archimedes principle which was illustrated in Figure 1(c). The density was decreased with increasing silicate content.

3.2. Tribology Study of Aluminum Hybrid Composites. The fly ash acts as a barrier to the movement of dislocations and thereby increases the strength and hardness of the composite. The fly ash particles to the aluminum melt significantly increase its abrasive wear resistance. The improvement in wear resistance is due to the hard alumina silicate constituent present in fly ash particles. From the view of material, influencing factors on friction force are mechanical properties of the matrix, hardness, chemical stability of the particles, composition, and strength of the interface. Interactions between these and tribological parameters (such as load and speed, environment, and the properties of the counter faces materials) are responsible for the overall response [21].

Thus, incorporation of silicate particles with fly ash to aluminum alloy improves the sliding wear resistance. The effects of both applied load and sliding velocity were investigated as a function of percentage of silicate with fly ash in aluminum alloy. The wear rate of the LM24/4 wt.\% fly ash and varying wt.\% of silicate hybrid composite is influenced by the load $(15,30,45,60$, and $75 \mathrm{~N})$ under sliding velocity $(0.75,1.5,2.25$, and $3 \mathrm{~m} / \mathrm{sec})$ which is illustrated in Figures $2(\mathrm{a})-2(\mathrm{~d})$. When increasing the load 15 to $75 \mathrm{~N}$, a similar trend in wear rate could be observed. The applied loads significantly affect the wear rate of LM24/silicate/fly ash hybrid composite and wear rate increases with increasing condition of applied load. The wear rate increases with increasing sliding velocity and it is less at hybrid composites as compared to base material LM24. However, at all load conditions, the wear resistance of the hybrid composites was superior to the matrix alloy and wear rate was raised from LM24/4 wt.\% silicate/4 wt.\% fly ash hybrid composite compared to LM24/4 wt.\% silicate/24 wt.\% fly ash hybrid composite. Figures illustrated that the reinforcement material of silicate increases at the wear rate is reduced.

When load applied is low, the wear loss is quite small, which increases with increase in applied load. It can be considered that it is quite natural for the weight loss to increase with load. The load further attains a transition value, at which wear mechanism changes from mild to severe wear. Figures 3(a)-3(d) illustrated the wear rates of the LM24/4 wt.\% fly ash and varying wt.\% of silicate hybrid composite as a function of the sliding velocities $0.75,1.5$, 2.25 , and $3 \mathrm{~m} / \mathrm{sec}$ at applied load of $15,30,45$, and $60 \mathrm{~N}$, respectively. The wear rate of the LM $24 / 4$ wt. $\%$ silicate/ 4 wt. $\%$ to LM $24 / 24$ wt.\% silicate/4 wt.\% fly ash hybrids composite increases with increasing sliding velocity. It is noted that the composite specimens exhibited significantly lower wear rates than the base alloy specimens.

3.3. Worn Surface Analysis. Worn surface at $75 \mathrm{~N}$ loads with unreinforced, $4 \%$ reinforced, and $16 \%$ reinforced composites is illustrated in Figure 4. The 16\% silicate reinforced 

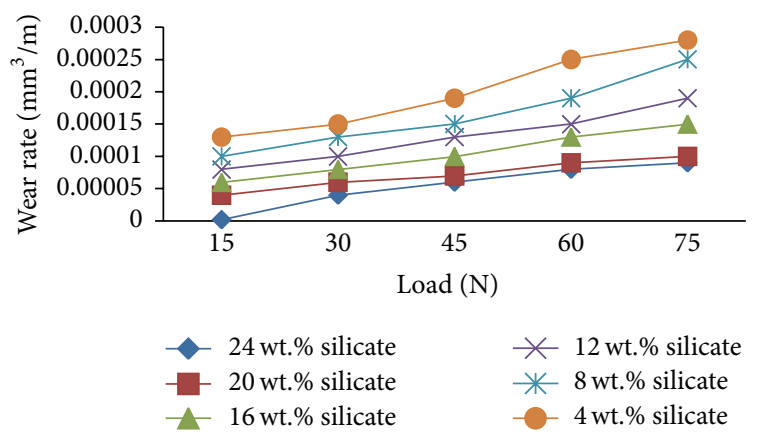

(a)

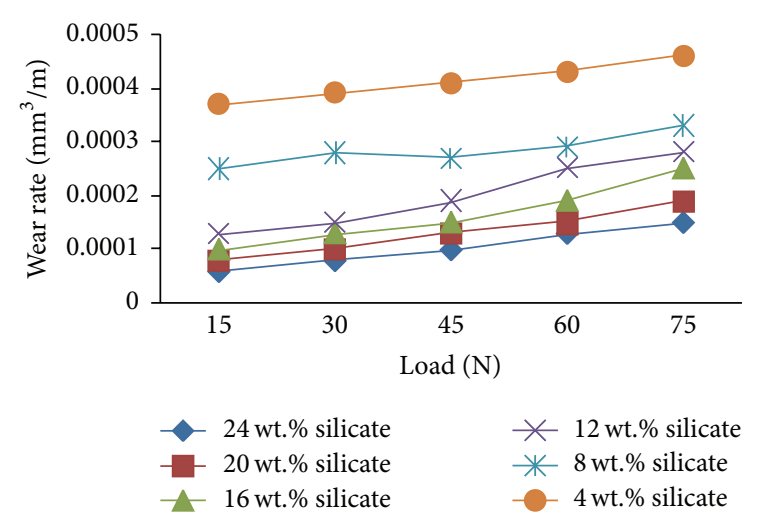

(c)

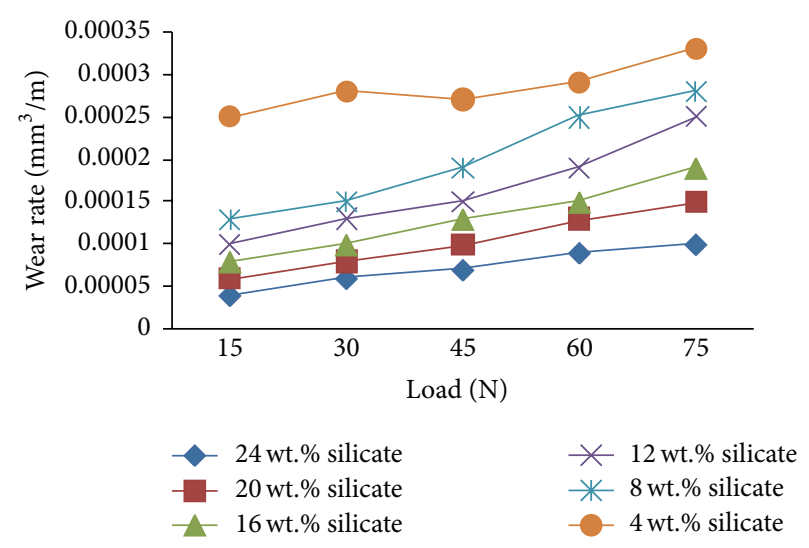

(b)

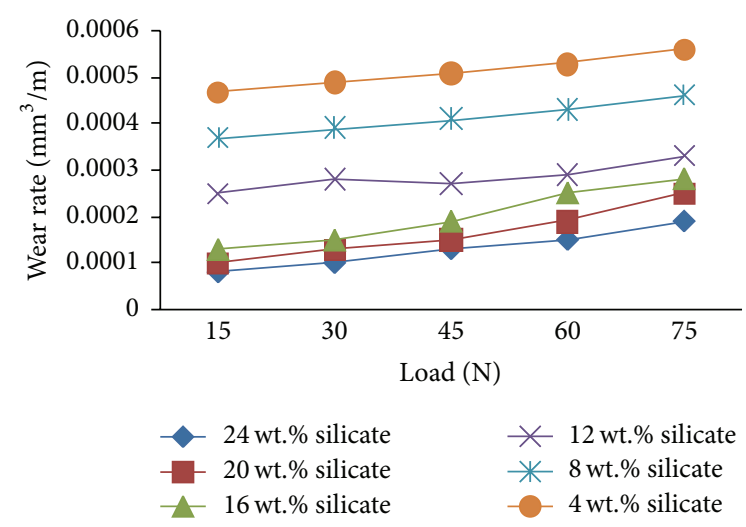

(d)

Figure 2: (a) Influence of load under sliding velocity $0.75 \mathrm{~m} / \mathrm{sec}$. (b) Influence of load under sliding velocity $1.5 \mathrm{~m} / \mathrm{sec}$. (c) Influence of load under sliding velocity $2.25 \mathrm{~m} / \mathrm{sec}$. (d) Influence of load under sliding velocity $3 \mathrm{~m} / \mathrm{sec}$.

LM24/silicate/fly ash hybrid composite had good wear resistance during high load of $75 \mathrm{~N}$ at sliding velocity of $1.5 \mathrm{~m} / \mathrm{s}$, while the unreinforced as well as the $4 \%$ reinforced composites get seized. Figure 4(a) shows that the worn surface of the unreinforced material removal during the process is in the form of small pieces resulting in the formation of flake type debris. The morphology of the worn-out surfaces changes from fine scratches to distinct grooves while increasing reinforced composites. The worn surfaces in some places reveal patches from where the material was removed from the surface of the material during the course of wear as shown in Figure 4(b).

Thus, confirm the positive effect of the reinforcing silicate particles and additionally its substance in decreasing wear rate of materials. As the $16 \%$ silicate reinforced is increased, the coefficient of friction decreases. The scanning electron micrographs of the samples indicate uniform distribution of the reinforcement particles in the matrix as shown in Figure 4(c).

3.4. Machining Study of Aluminum Hybrid Composites. Based on Taguchi's $\mathrm{L}_{9}$ orthogonal array, drilling experiments were conducted on LM24/24 wt.\% silicate/24 wt.\% fly ash hybrid composite by HSS twist drill coated with TiAlN. The experimental results such as surface roughness and cutting force were collected for each trial and it is shown in Table 3. The $\mathrm{S} / \mathrm{N}$ ratio for smaller the better type category is given by

$$
\mathrm{S} / \mathrm{N} \text { ratio }(\eta)=-10 \log _{10}\left(\frac{1}{n} \sum_{i=1}^{n} y_{i j}{ }^{2}\right) \text {. }
$$

The Taguchi analysis for surface roughness given in Table 4 clearly shows that the surface roughness delta value for point angle is 6.634 and cutting speed is 6.265 . It can be seen that the point angle is the strongest effect on surface roughness followed by cutting speed. Optimal parameter for minimization of the surface roughness cutting speed is set as $30 \mathrm{~m} / \mathrm{min}$, feed is set as $1.5 \mathrm{~mm} / \mathrm{rev}$, and point angle is set as 140 degrees. The Taguchi analysis for cutting force is given in Table 4, and it clearly shows that the cutting force delta value for feed is 14.86 and cutting speed is 10.31 . It can be seen that the feed is the strongest effect on cutting force followed by cutting speed. Optimal parameters for minimization of the cutting force are cutting speed set as $30 \mathrm{~m} / \mathrm{min}$, feed is set to as $0.5 \mathrm{~mm} / \mathrm{rev}$, and point angle is set as 120 degrees.

Table 5 shows the results of ANOVA for aluminum hybrid composites and analysis was carried out for a confidence level of $95 \%$ (significance level of $\alpha=0.05$ ). The ANOVA for surface roughness on aluminum hybrid composites is given in Table 5; it clearly shows that the point angle most 

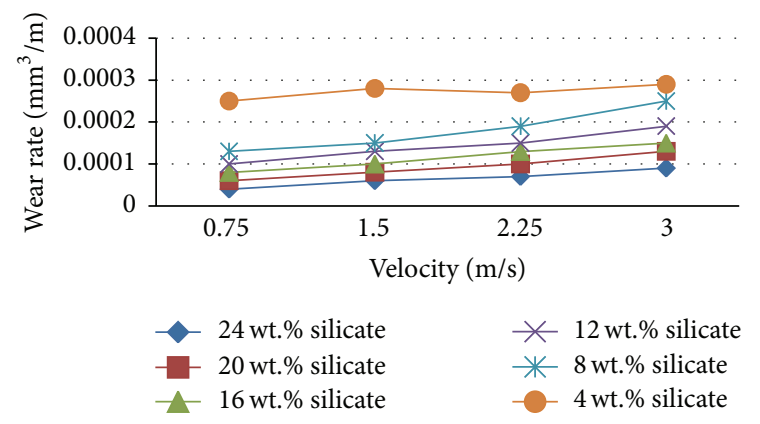

(a)

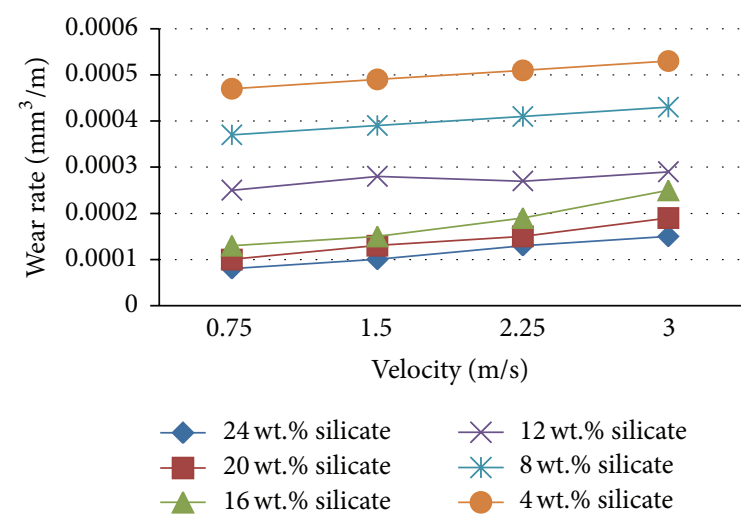

(c)

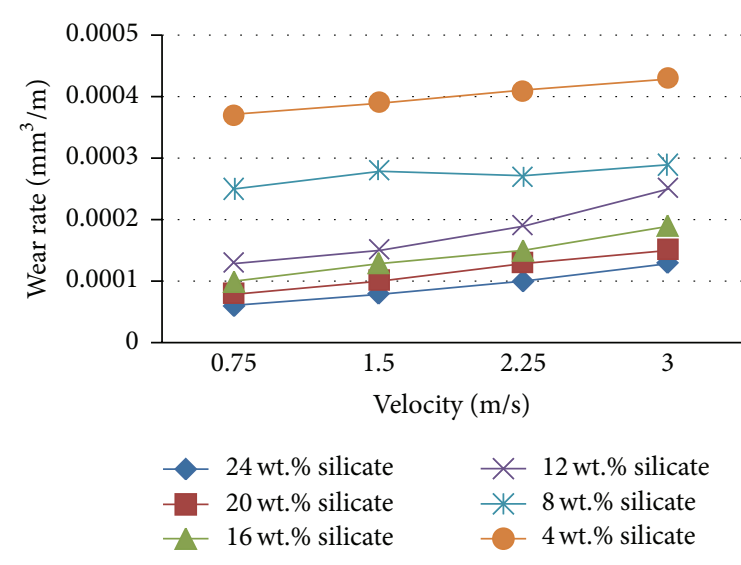

(b)

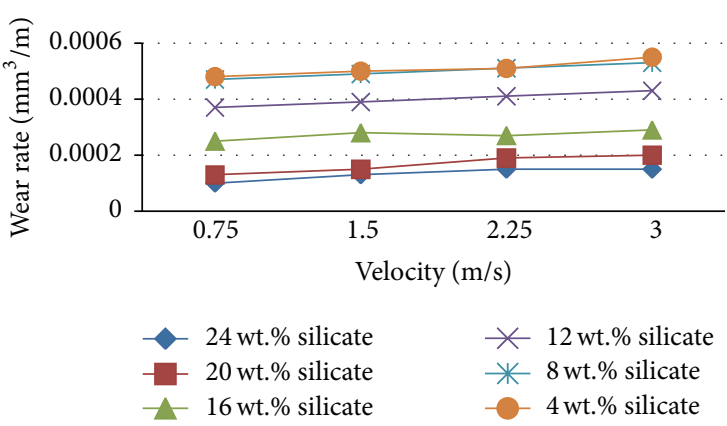

(d)

FIGURE 3: (a) Influence of sliding velocity under load $15 \mathrm{~N}$. (b) Influence of sliding velocities under load $30 \mathrm{~N}$. (c) Influence of sliding velocity under load 45 N. (d) Influence of sliding velocity under load $60 \mathrm{~N}$.

TABLE 3: Experimental result of aluminum hybrid composites.

\begin{tabular}{lcccc}
\hline Trial & $\mathrm{Ra}(\mu \mathrm{m})$ & $\mathrm{S} / \mathrm{N}$ & $\mathrm{Fc}(\mathrm{N})$ & $\mathrm{S} / \mathrm{N}$ \\
\hline 1 & 6.66 & -16.47 & 90.57 & -39.14 \\
2 & 2.84 & -9.07 & 237.66 & -47.52 \\
3 & 1.05 & -0.42 & 453.37 & -53.13 \\
4 & 5.53 & -14.85 & 169.01 & -44.56 \\
5 & 4.63 & -13.31 & 522.03 & -54.35 \\
6 & 4.92 & -13.84 & 1169.23 & -61.36 \\
7 & 4.84 & -13.70 & 257.27 & -48.21 \\
8 & 7.1 & -17.03 & 1061.36 & -60.52 \\
9 & 5.03 & -14.03 & 1257.48 & -61.99 \\
\hline
\end{tabular}

significantly affects the surface roughness with $F: P$ value of $4.68: 0.176$ followed by the cutting speed with $F: P$ value of $2.97: 0.252$. The ANOVA for cutting force on aluminum hybrid composites is given in Table 5; it clearly shows that the feed is most significantly affected by the cutting force with $F: P$ value of 108.47:0.009 followed by the cutting speed with $F: P$ value of $63.17: 0.016$. The models are then checked using a numerical method employing the coefficient of determination $\left(R^{2}\right)$ and adjusted $R^{2}\left(R^{2}\right.$ adj). $R^{2}$ shows how much of the observed variability in the data is accounted by
TABLE 4: Taguchi analysis of aluminum hybrid composites.

\begin{tabular}{lcccccc}
\hline Level & \multicolumn{3}{c}{ SR } & & \multicolumn{3}{c}{ FC } \\
& $A$ & $B$ & $C$ & $A$ & $B$ & $C$ \\
\hline 1 & $\mathbf{- 8 . 6 5 3}$ & -15.007 & -15.778 & $-\mathbf{4 6 . 6 0}$ & $-\mathbf{4 3 . 9 7}$ & -53.67 \\
2 & -14.002 & -13.134 & -12.651 & -53.42 & -54.13 & $-\mathbf{5 1 . 3 6}$ \\
3 & -14.918 & $-\mathbf{9 . 4 3 1}$ & $-\mathbf{9 . 1 4 4}$ & -56.91 & -58.83 & -51.90 \\
Delta & 6.265 & 5.575 & 6.634 & 10.31 & 14.86 & 2.32 \\
Rank & 2 & 3 & 1 & 2 & 1 & 3 \\
\hline
\end{tabular}

the model, while $R^{2}$ adj modifies $R^{2}$ by taking into account the quantity of predictors in the model. The response surface models are developed in this study with values of $R^{2}$, say 91.04\% and $99.49 \%$ for surface roughness and cutting force, respectively. Furthermore, $R^{2}$ adj close to the $R^{2}$ values insure a satisfactory adjustment of the quadratic models to the experimental data.

\section{Conclusion}

Particulate reinforced LM24/silicate/fly ash hybrid composites were fabricated by the vortex method. The mechanical 


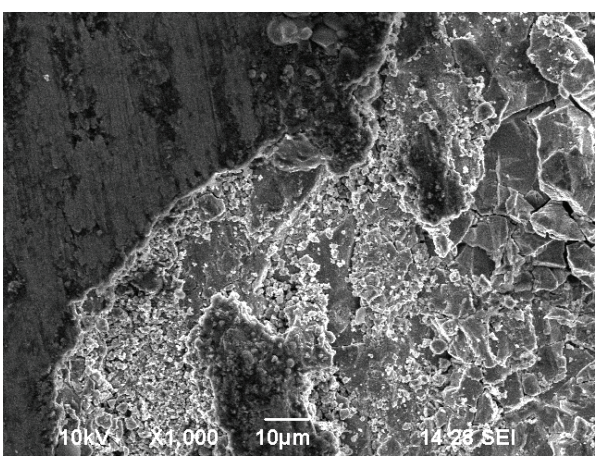

(a)

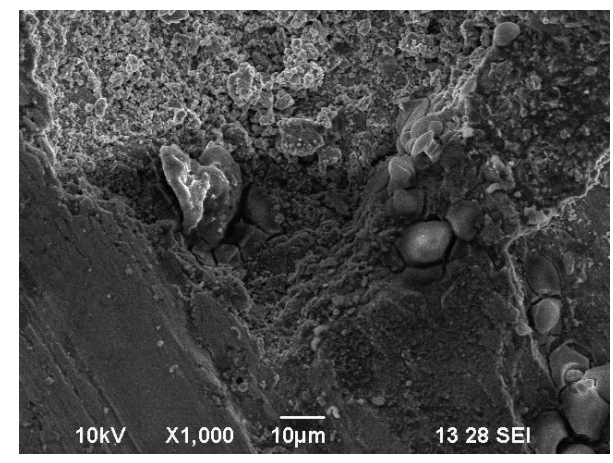

(b)

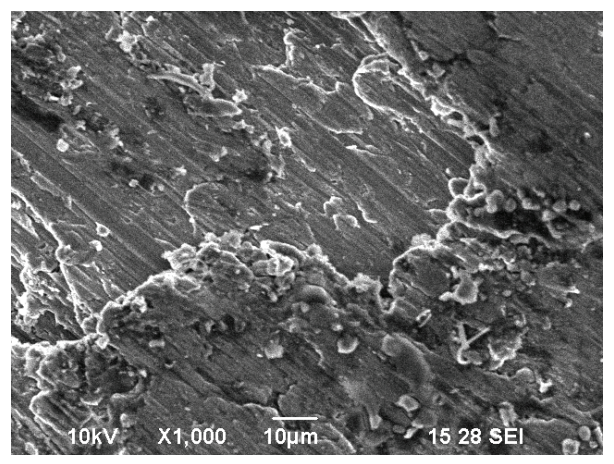

(c)

FIGURE 4: Worn surface: (a) unreinforced; (b) 4\% reinforced; (c) 16\% reinforced.

TABLE 5: Analysis of variance of aluminum hybrid composites.

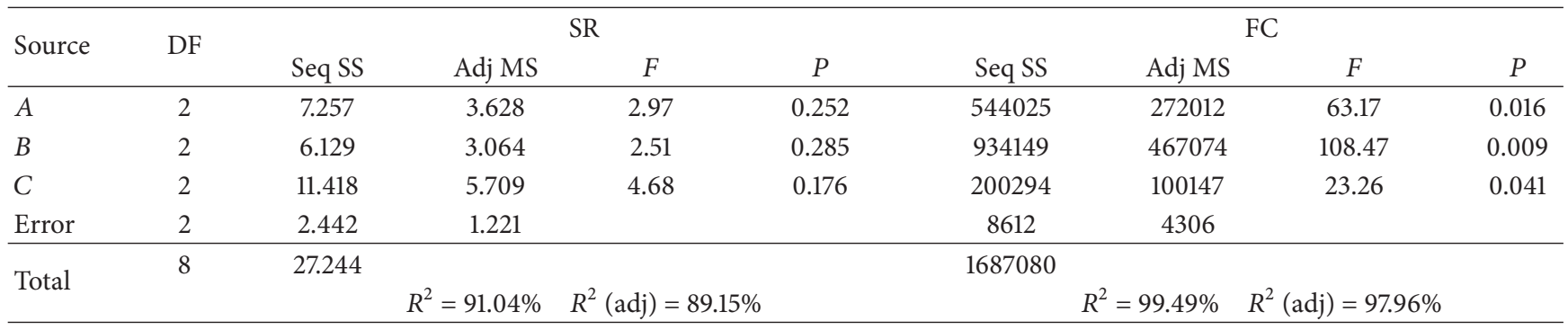

and wear properties of aluminum hybrid composites are significantly changed by varying the amount of silicate therein. The final conclusions acquired were as follows:

(i) LM24/silicate/fly ash hybrids composite is increasing the mechanical properties and reinforced silicate particle exhibited reducing the sliding wear loss compared to the low reinforced alloy. The wear loss decreases with increase in silicate content.

(ii) The hardness of the LM24/silicate/fly ash hybrid composite increases with the addition of silicate and it is higher than that of base alloy. The tensile strength was increased with increasing silicate content. The fly ash addition normally decreases the strength but with the addition of silicate particles, improving the mechanical properties. The density was decreased with increasing silicate content. (iii) The wear rate of the composite is influenced by the load and sliding velocity of the pin on disc and worn surface of the aluminum hybrid composites is good compared to the low weight percentage of the silicate particle reinforcement.

(iv) Optimal parameters for minimization of the surface roughness's cutting speed are set as $30 \mathrm{~m} / \mathrm{min}$, feed is set as $1.5 \mathrm{~mm} / \mathrm{rev}$, and point angle is set as 140 degrees. Optimal parameter for minimization of the cutting force's cutting speed is set as $30 \mathrm{~m} / \mathrm{min}$, feed is set as $0.5 \mathrm{~mm} / \mathrm{rev}$, and point angle is set as 120 degrees.

\section{Competing Interests}

The authors declare that they have no competing interests. 


\section{References}

[1] S. Basavarajappa, G. Chandramohan, K. Mukund, M. Ashwin, and M. Prabu, "Dry sliding wear behavior of Al 2219/SiCpGr hybrid metal matrix composites," Journal of Materials Engineering and Performance, vol. 15, no. 6, pp. 668-674, 2006.

[2] H. S. Anilkumar, H. S. Hebbar, and K. S. Ravishankar, "Mechanical properties of fly ash reinforced aluminum alloy composites," International Journal of Mechanical and Materials Engineering, vol. 6, pp. 41-45, 2011.

[3] V. C. Uvaraja, N. Natarajan, K. Sivakumar, S. Jegadheeshwaran, and S. Sudhakar, "Tribological behavior of heat treated Al 7075 aluminium metal matrix composites," Indian Journal of Engineering \& Materials Sciences, vol. 22, pp. 51-61, 2014.

[4] F. Q. Hu, F. Y. Cao, B. Y. Song et al., "Surface properties of $\mathrm{SiCp} / \mathrm{Al}$ composite by powder-mixed EDM," in Proceedings of the 17th CIRP Conference on Electro Physical and Chemical Machining (ISEM '13), pp. 101-106, April 2013.

[5] D. Kuc and J. Cebulski, "Plastic behavior and microstructure characterization high manganese aluminium alloyed steel for the automotive industry," Journal of Achievements in Materials and Manufacturing Engineering, vol. 51, no. 1, pp. 14-21, 2012.

[6] K. M. Patel, P. M. Pandey, and P. Venkateswara Rao, "Surface integrity and material removal mechanisms associated with the EDM of $\mathrm{Al}_{2} \mathrm{O}_{3}$ ceramic composite," International Journal of Refractory Metals \& Hard Materials, vol. 27, no. 5, pp. 892-899, 2009.

[7] S. Mitrovic, M. Babic, F. Zivic, I. Bobic, and D. Dzunic, "Nanotribology investigations of composites based on Za-27 alloy reinforced by $\mathrm{Al}_{2} \mathrm{O}_{3}$ particles," Tribology in Industry, vol. 30, pp. 33-39, 2008.

[8] G. Ranganath, S. C. Sharma, and M. Krishna, "Dry sliding wear of garnet reinforced zinc/aluminium metal matrix composites," Wear, vol. 251, no. 1-12, pp. 1408-1413, 2001.

[9] K. Ravi Kumar, K. M. Mohanasundaram, G. Arumaikkannu, and R. Subramanian, "Analysis of parameters influencing wear and frictional behavior of aluminum-fly ash composites," Tribology Transactions, vol. 55, no. 6, pp. 723-729, 2012.

[10] J. Sulardjaka and M. W. Wildan, "Wear resistance of carbothermally reduced of fly ash reinforced aluminum composite," International Journal of Mechanical \& Mechatronics Engineering, vol. 10, pp. 15-21, 2010.

[11] S. Gopalakannan, T. Senthilvelan, and S. Ranganathan, "Statistical optimization of EDM parameters on machining of aluminum Hybrid Metal Matrix composite by applying Taguchi based Grey analysis," Journal of Scientific and Industrial Research, vol. 72, no. 6, pp. 358-365, 2013.

[12] R. Karthikeyan, Analysis and optimization of machining characteristics of AI/SiC particulate composites [Ph.D. thesis], Annamalai University, Chidambaram, India, 1999.

[13] M. G. Anantha Prasad and B. Nityanand, "Study of microstructure and mechanical behavior of aluminum/garnet/carbon hybrid metal matrix composites fabricated by chill casting method," Journal of Materials Science and Chemical Engineering, vol. 3, no. 3, pp. 1-8, 2014.

[14] N. Radhika, R. Subramanian, and P. S. Venkat, "Tribological behavior of aluminium/alumina/graphite hybrid metal matrix composite using Taguchi's techniques," Journal of Minerals and Material Characterization and Engineering, vol. 10, no. 5, pp. 427-443, 2011.

[15] D. Kumar, H. Roy, and B. K. Show, “Tribological behavior of an aluminum matrix composite with $\mathrm{Al}_{4} \mathrm{SiC}_{4}$ reinforcement under dry sliding condition," Tribology Transactions, vol. 58, no. 3, pp. 518-526, 2015.

[16] S. Sivakumar, K. P. Padmanaban, and M. Uthayakumar, "Wear behavior of the $\mathrm{Al}$ (LM24)-garnet particulate composites under dry sliding conditions," Proceedings of the Institution of Mechanical Engineers, Part J: Journal of Engineering Tribology, vol. 228, no. 12, pp. 1410-1420, 2014.

[17] K. Palanikumar, T. Sasimurugan, and N. Manogaran, "Optimization of machining characteristics of aluminum silicon carbide composites using Taguchi technique," in Proceedings of the International Conference on Advances in Materials, Product Design and Manufacturing Systems (ICMPM '05), pp. 772-778, Tamil Nadu, India, 2005.

[18] J. Paulo Davim, "Study of drilling metal-matrix composites based on the Taguchi techniques," Journal of Materials Processing Technology, vol. 132, no. 1-3, pp. 250-254, 2003.

[19] A. Manna and B. Bhattacharayya, "A study on machinability of Al/SiC-MMC," Journal of Materials Processing Technology, vol. 140, no. 1-3, pp. 711-716, 2003.

[20] G. Tosun and M. Muratoglu, "The drilling of $\mathrm{Al} / \mathrm{SiC}_{\mathrm{p}}$ metalmatrix composites. Part II: workpiece surface integrity," Composites Science and Technology, vol. 64, no. 10-11, pp. 1413-1418, 2004.

[21] Sudarshan and M. K. Surappa, "Synthesis of fly ash particle reinforced A356 Al composites and their characterization," Materials Science and Engineering A, vol. 480, no. 1-2, pp. 117124, 2008. 

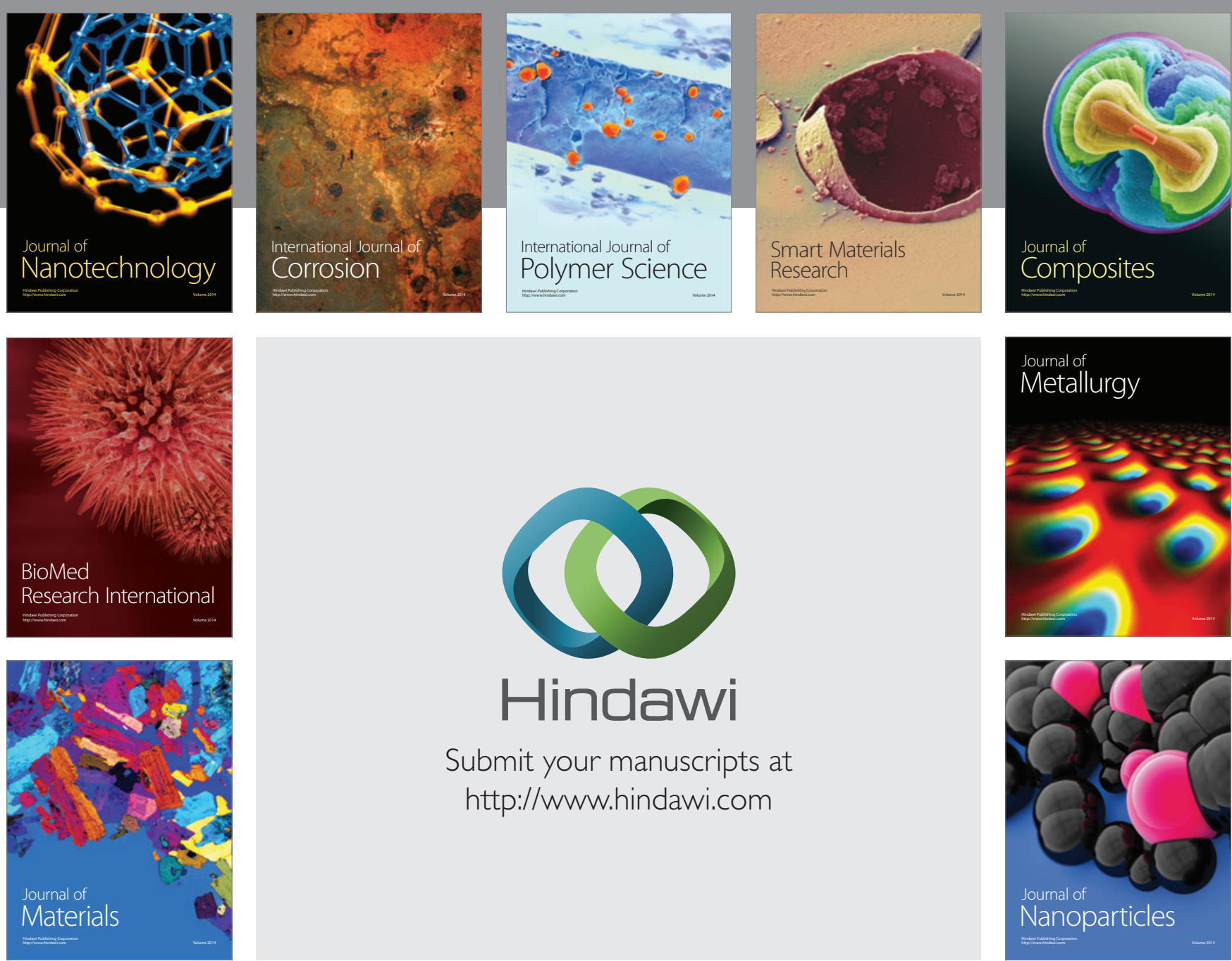

\section{Hindawi}

Submit your manuscripts at

http://www.hindawi.com

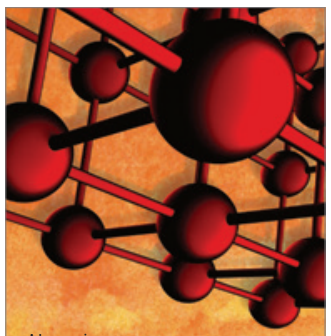

Materials Science and Engineering
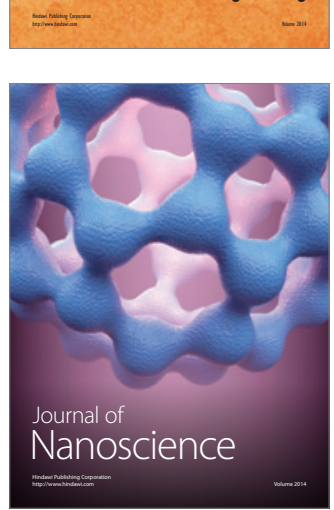
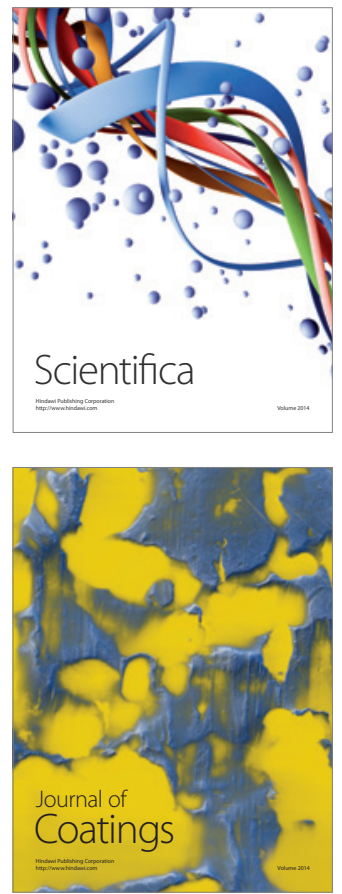
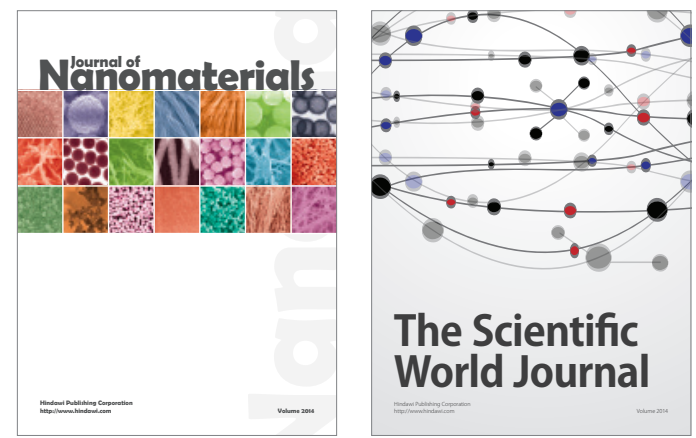

The Scientific World Journal
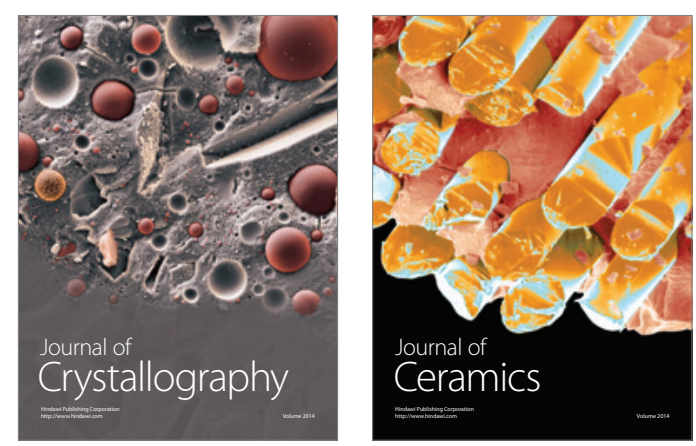
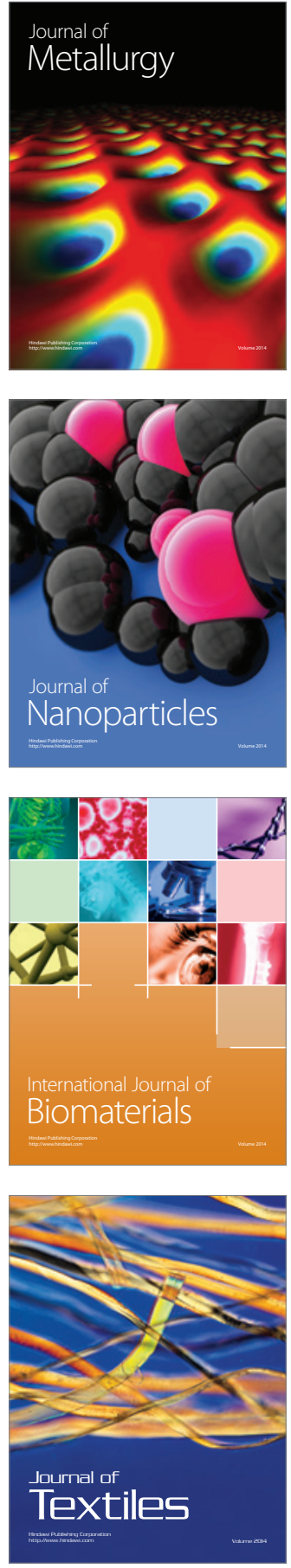